\title{
Money Talks: Team Variables and Player Positions that Most Influence the Market Value of Professional Male Footballers in Europe
}

\author{
Jose Luis Felipe ${ }^{1}\left(\mathbb{D}\right.$, Alvaro Fernandez-Luna ${ }^{1, *}$, Pablo Burillo ${ }^{1}{ }^{(D}$, Luis Eduardo de la Riva ${ }^{1}$, \\ Javier Sanchez-Sanchez ${ }^{1}(\mathbb{C})$ and Jorge Garcia-Unanue ${ }^{2}$ (I) \\ 1 School of Sports Sciences, Universidad Europea de Madrid, Calle Tajo S/N, 28670 Villaviciosa de Odón, \\ Madrid, Spain; joseluis.felipe@universidadeuropea.es (J.L.F.); pablo.burillo@universidadeuropea.es (P.B.); \\ delariva95@gmail.com (L.E.d.1.R.); javier.sanchez2@universidadeuropea.es (J.S.-S.) \\ 2 IGOID Research Group, University of Castilla-La Mancha, Campus Antigua Fábrica de Armas, 45071 Toledo, \\ Spain; Jorge.GarciaUnanue@uclm.es \\ * Correspondence: alvaro.fernandez2@universidadeuropea.es
}

Received: 2 April 2020; Accepted: 30 April 2020; Published: 3 May 2020

check for updates

\begin{abstract}
The aim of this paper is to analyse different interactions of the variables (age, position, or quality of the team and the league) and the crowdsourcing Transfermarkt values of male players in the top European leagues. All players $(n=2259)$ in the five most highly valued European leagues-Spain, England, Italy, France, and Germany-from the 2017/2018 season were included in this study. Data were retrieved from the open-source football database (Transfermarkt). The present economic value (VPRESENT) and maximum economic value (VMAX) of all players with professional contracts were registered. Regression analysis evidenced a significant influence of the level of the team, the birth month, the league, the playing position and the age of the player on mean and maximum economic value $(p<0.05)$. This analysis confirms that the players participating in the UEFA Champions League, Premier League teams, playing as attacking midfielders, and born in the first quarter of the year are the most economically valued in terms of both current value (R2 of 0.33 ) and maximal value ( $\mathrm{R} 2$ of 0.36 ). Therefore, international football entities must take into account the financial balance between competitions-and not only at the domestic level, as the attractiveness and balance of European competitions may be directly affected.
\end{abstract}

Keywords: elite football; economic value; playing position; competitive level

\section{Introduction}

In professional male football, movements of players among clubs involve, in most cases, economic transfers whose underlying inflation seems to have no limit. Age [1-3], the player's position [4-6], sport performance (as goals scored, passes, assistances, etc.) [7-9], and physical characteristics [1-10] are highly studied variables used by managers for hiring and for the player's salary. Moreover, other studies point out that variables that are little related to sport, such as nationality [11-13] or the popularity of the player $[14,15]$, can influence on signing a player.

The market value of a player has been defined as 'an estimate of the amount of money a club would be willing to pay in order to make [an] athlete sign a contract, independent of an actual transaction' [16]. This market value gives useful information for clubs according to the estimated monetary value of players, crucial in transfer negotiations. This value has been traditionally estimated by clubs and journalists. However, the role of football fans has become more important [17] through the use of new technologies and the Internet. This phenomenon is also called crowdsourcing, and it has been applied 
in other business areas, as well [18]. Thus, the most important example of crowdsourcing in today's football business is Transfermarkt.

Transfermarkt (www.transfermarkt.com) is a German-based website owned by the digital European publishing house Axel Springer SE. It is the leading website on the football transfer market. The site offers, among other general football-related data, the estimations of market value at the individual and team levels for most professional football leagues [17]. The website, which establishes the market value of players based on registered users, has been used in other recent research [19] as a reliable indicator related to game performance [16] and as a good predictor of the real value of players [20]. In these studies, researchers evaluate the effect of variables like age, position [20,21], precision, scoring, flexibility, assertion and other aspects as team coach, and public attention [16]. In addition, other authors analysed the impact of players' social media activity on their perceived market value [22]. However, there are some controversial aspects regarding the possible bias in the estimations of players' market value. The main issue is the lack of knowledge and experience, as well as the impulsive behaviour of some registered users [23]. Finally, possible attempts at manipulation by agents in lower category leagues should also be considered. In order to confront these problems, Transfermarkt applies the 'judge principle', which consists of the selection of certain registered users who have demonstrated enough knowledge and participation to be considered the most reliable sources to establish the value of players [16]. These 'judges' analyse and weigh up the opinion of other users and act like a 'filter'. Using this procedure, Transfermarkt erases the judgements of inexperienced users, although this is not a 'democratic' system. Despite this strategy, there are major concerns in the literature about who these 'judges' are and how they are selected, as well as how Transfermarkt establishes the final market value of players. Nevertheless, a recent study carried out using Major League Soccer (MLS) data suggested that Transfermarkt values are excellent proxies for players' salaries. Thus, authors encourage researchers to use information from sources like Transfermarkt in their empirical studies [24].

Muller and colleagues identify several limitations to Transfermarkt's evaluation system, highlighting the huge number of evaluations of top league players to the detriment of minor league players, the lax criteria used for player evaluation (even a nonmandatory manual for assessment exists), and finally, the dependence on a high number of assessments, which require several matches to give an adjusted market value (taking between 6 and 12 months to give an estimated market value) [17]. Moreover, they suggest that Transfermarkt does not provide a competitive advantage for clubs and players in order to negotiate new contracts, since the database is public. This explains why the authors have tried to adjust the model according to other interesting data, such as performance in the field (goals, assists, dribbles, tackles, etc.) and the presence of players on social media, showing that an adjusted model using this data is more efficient than the evaluation of Transfermarkt users by itself. Other authors have applied an adjusted model using the forecasting data and have demonstrated that 'crowd wisdom' is more efficient to predict football results than the Federation Internationale de Football Association (FIFA) or the ELO-Chess rankings [19]. In this vein, broadcasting rights directly affect the income of football teams (and players' real market value), and these rights, in turn, vary depending on the country [25]. However, there is no evidence about how the different national leagues, and their broadcasting rights, affect the perceived market value of the player. Recent articles have explored the relation between perceived market value of players and the relative age effect (RAE), reaching no clear conclusions [26,27]. To sum up, there are divided opinions about the real efficiency and scientific value of Transfermarkt, and it consistently depends on the variables used in the different research.

Thus, as we have mentioned, the literature supplies no evidence about the relation of the estimated value showed in Transfermarkt and other important variables, such as football results, league quality, and pitch position of players. In order to provide knowledge in this field of study, the main objective of this paper is to analyse how demographic and performance variables (age, position, or quality 
of the team and the league) can affect the crowdsourcing Transfermarkt values of players in the top European leagues.

\section{Materials and Methods}

A retrospective cohort research was performed. All players $(n=2259)$ in the five most highly valued European leagues-Spain (LaLiga), England (Premier League), Italy (Serie A), France (Ligue 1), and Germany (Bundesliga) — from the 2017/2018 season were included in this study. All the data used in this study were retrieved from the open-source football database Transfermarkt. The present economic value (value 2018, VPRESENT) and maximum economic value (VMAX) of all players with professional contracts were registered. The economic value of players was determined using an algorithm according to the age, height, position, dominant leg, nationality, playing time, goals, assists, passes, dribbles, duels, fouls, yellow and red cards, popularity, frequency with which the players are cited in social media, and the number of links on the Internet of the players. Transfermarkt has shown itself to be a valid and useful data source for research [16].

The data of economic value were classified into different categories. Firstly, players were ranked at a high level or low level based on the final position of their teams in the 2017/2018 season (teams ranked in the top half of their league table were considered high level, and teams ranked in the bottom half were classified as low level). Secondly, players were classified into three groups based on the final position of their team in the 2017/2018 season and their team's classification (or lack thereof) in European competitions (UEFA Champions League and UEFA Europa League). Thirdly, players were also classified into four groups, according to their date of birth, in order to control for the possible influence of relative age. Fourthly, players were divided according to their playing position: forwards; attacking midfielders; defensive midfielders; defenders; and goalkeepers. Finally, players were classified according to the league to which their team belonged in the reference season. The classification by league was made for all players and teams and only for players of the teams reaching qualifying positions for the UEFA Champions League at the end of the season.

The data analysis was developed with Stata 14.0 for Windows. A one-way analysis of variance (ANOVA) and Bonferroni post hoc test was performed to compare the VPRESENT and VMAX for each of the groupings created: level; classification in European competitions; term of birth; playing position; league in which the player plays; and league in which the footballer plays (first comparison with all players and second comparison including teams qualifying for the UEFA Champions League). The confidence interval of the differences (CI at 95\%) was included, and the effect size was calculated to identify the magnitude of changes (ES; Cohen's d) [28]. The ES was evaluated using the following criteria: 0 to $0.2=$ trivial; 0.2 to $0.5=$ small; 0.5 to $0.8=$ moderate; and $>0.8=$ large [24]. Finally, a linear regression model was estimated using ordinary least squares (OLS), which included all previous categorical variables as well as age, with the objective of comparing the influence of each of the categories and their combined level of explanation of economic value. The model was replicated for VPRESENT and VMAX. Multicollinearity was evaluated using the variance inflation factor (VIF) as well as the normality of the errors, fulfilling the assumptions for the linear regression. However, the models presented heteroscedasticity problems, so the estimates were performed with robust standard errors. The level of significance was established at $p<0.05$ for all tests.

\section{Results}

The variance analysis revealed a higher mean (+9.47 mill; CI 95\%: 8.40 to 10.55; ES: $0.86 ; p<0.001$; Table 1) and maximum (+10.53 mill; CI 95\%: 9.41 to 11.66; ES: $0.89 ; p<0.001)$ economic value of players in teams at the top of the table in comparison to teams situated at the bottom of the league. Teams playing in the UEFA Champions League evidenced a higher VMEAN than UEFA Europa League teams (+11.98 mill; CI 95\%: 9.91 to 14.03; ES: 0.66; $p<0.001$ ) and teams not playing in either European competition (+17.90 mill; CI 95\%: 16.32 to 19.47; ES: $1.27 ; p<0.001$ ). Economic value was similar according to the month of birth $(p>0.05)$. Finally, the comparison among playing positions showed 
a significantly higher VMEAN and VMAX in attacking midfielders in comparison to goalkeepers (VMEAN: +8.31 mill; CI 95\%: 5.13 to 11.49; ES: 0.56; VMAX: +9.02 mill; CI 95\%: 5.67 to 12.36; ES: 0.58); defenders (VMEAN: +6.04 mill; CI 95\%: 3.66 to 8.42; ES: 0.40; VMAX: +7.05 mill; CI 95\%: 4.54 to 9.56; ES: 0.45); midfielders (VMEAN: +4.73 mill; CI 95\%: 2.15 to 7.32; ES: 0.28; VMAX: +5.50 mill; CI 95\%: 2.77 to 8.23; ES: 0.32); and forwards (VMEAN: +3.39 mill; CI 95\%: 0.60 to 6.19; ES: 0.18; VMAX: +3.34 mill; CI 95\%: 0.39 to 6.28; ES: 0.17). However, no differences were found between midfielders and forwards $(p>0.05)$.

Table 1. Mean and maximum value according to team position, competition, birth month, and playing position in professional football players.

\begin{tabular}{cccccccc}
\hline & $\mathbf{n}$ & \multicolumn{3}{c}{ Mean Value (€ mill) } & \multicolumn{2}{c}{ Maximum Value (€ mill) } \\
\hline Top Team & 1122 & 13.11 & \pm & $17.95^{*}$ & 15.96 & \pm & $18.54^{*}$ \\
Bottom Team & 1137 & 3.64 & \pm & 4.15 & 5.43 & \pm & 5.23 \\
Champions League Team (a) & 427 & 21.92 & \pm & $23.57^{\mathrm{b}, \mathrm{c}}$ & 25.76 & \pm & $23.62^{\mathrm{b}, \mathrm{c}}$ \\
Europa League Team (b) & 356 & 9.95 & \pm & $12.48^{\mathrm{c}}$ & 12.25 & \pm & $12.76^{\mathrm{c}}$ \\
No Competition Team (c) & 1476 & 4.03 & \pm & 4.68 & 5.91 & \pm & 5.94 \\
Birthday Quarter 1 (a) & 697 & 8.78 & \pm & 14.68 & 11.10 & \pm & 15.32 \\
Birthday Quarter 2 (b) & 577 & 8.64 & \pm & 15.24 & 10.70 & \pm & 15.81 \\
Birthday Quarter 3 (c) & 543 & 7.49 & \pm & 11.50 & 10.13 & \pm & 12.80 \\
Birthday Quarter 4 (d) & 414 & 8.63 & \pm & 13.39 & 10.93 & \pm & 13.99 \\
Goalkeeper (a) & 230 & 4.57 & \pm & 8.19 & 6.77 & \pm & 9.02 \\
Defender (b) & 751 & 6.84 & \pm & 8.82 & 8.73 & \pm & 9.40 \\
Midfielder (c) & 493 & 8.15 & \pm & $12.67^{\mathrm{a}}$ & 10.28 & \pm & $12.76^{\mathrm{a}}$ \\
Attacking Midfielder (d) & 400 & 12.88 & \pm & $21.022^{\mathrm{a}, \mathrm{b}, \mathrm{c}, \mathrm{e}}$ & 15.78 & \pm & $21.84^{\mathrm{a}, \mathrm{b}, \mathrm{c}, \mathrm{e}}$ \\
Forward (e) & 357 & 9.49 & \pm & $16.11^{\mathrm{a}, \mathrm{b}}$ & 12.45 & \pm & $17.08^{\mathrm{a}, \mathrm{b}}$ \\
\hline
\end{tabular}

* $, a, b, c, d, e$, significant differences $p<0.05$.

Comparative analysis of the top five leagues in Europe revealed a higher economic value of the English Premier League teams than their German (VMEAN: +6.25 mill; CI 95\%: 3.66 to 8.83; ES: 0.46; VMAX: +6.31 mill; CI 95\%: 3.58 to 9.04; ES: 0.43); Spanish (VMEAN: +4.69 mill; CI 95\%: 2.19 to 7.19; ES: 0.27; VMAX: +4.88 mill; CI 95\%: 2.24 to 7.51; ES: 0.28); French (VMEAN: +9.17 mill; CI 95\%: 6.63 to 11.70; ES: 0.67; VMAX: +9.84 mill; CI 95\%: 7.15 to 12.53; ES: 0.68); and Italian (VMEAN: +6.6 mill; CI 95\%: 4.14 to 9.06; ES: 0.47; VMAX: +6.75 mill; CI 95\%: 4.16 to 9.34; ES: 0.47) counterparts. However, when the Champions League teams were filtered, no differences were found between Premier League and LaLiga teams $(p>0.05$; Figure 1).

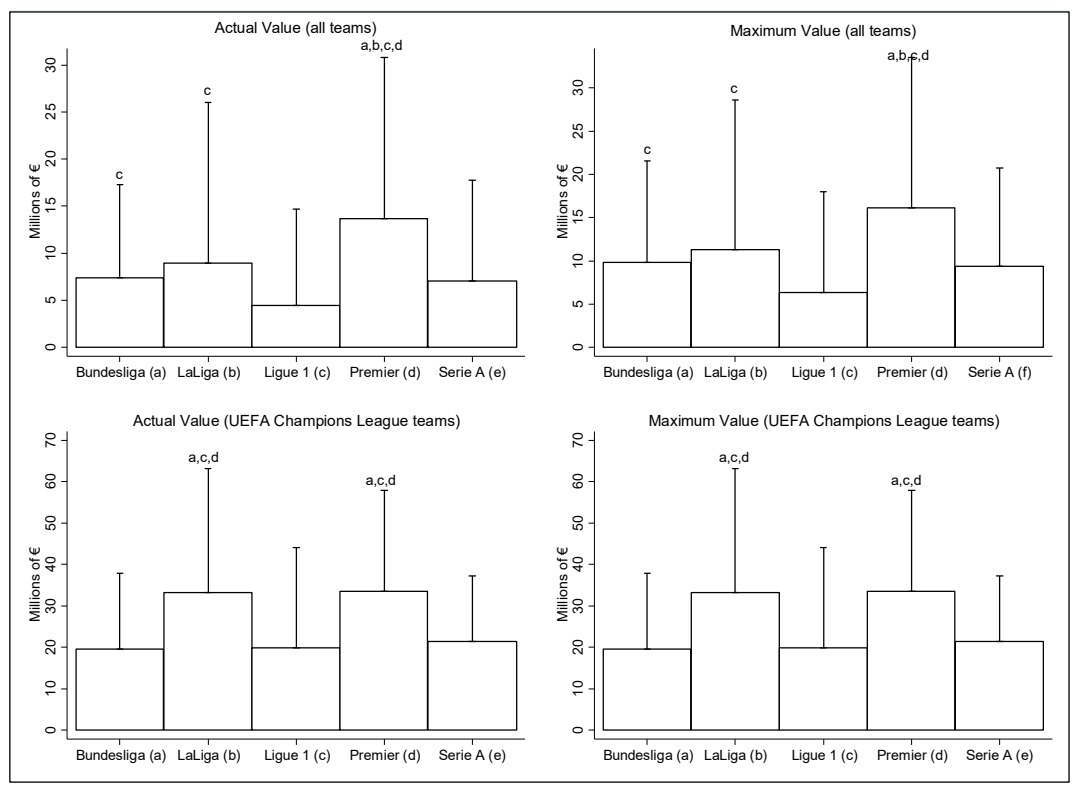

Figure 1. Mean and maximum value according to the League and the European Champions teams. $\mathrm{a}, \mathrm{b}, \mathrm{c}, \mathrm{d}, \mathrm{e}$, significant differences $p<0.05$. 
Finally, the regression analysis (Table 2) evidenced a significant influence of the level of the team, the birth month, the league, the playing position, and the age of the player on mean and maximum economic value $(p<0.05)$. This analysis confirms that the players participating in UEFA Champions League teams of the Premier League, playing as attacking midfielders, and born in the first quarter of the year are the most economically valued in terms of both current value $\left(R^{2}\right.$ of 0.33$)$ and maximal value $\left(R^{2}\right.$ of 0.36$)$.

Table 2. Linear regression analysis of mean and maximum economic value according to the omitted contextual variable.

\begin{tabular}{|c|c|c|c|c|c|c|}
\hline & \multicolumn{3}{|c|}{ Current Value } & \multicolumn{3}{|c|}{ Maximum Value } \\
\hline & Coef. & Std. Err. & $p$ & Coef. & Std. Err. & $p$ \\
\hline \multicolumn{7}{|l|}{ Champions League Team } \\
\hline Europa League Team & -11.80 & 1.24 & $<0.001$ & -13.32 & 1.24 & $<0.001$ \\
\hline No Competition Team & -17.71 & 1.09 & $<0.001$ & -19.87 & 1.09 & $<0.001$ \\
\hline \multicolumn{7}{|l|}{ Birthday Quarter 1} \\
\hline Birthday Quarter 2 & -0.32 & 0.69 & 0.649 & -0.82 & 0.70 & 0.24 \\
\hline Birthday Quarter 3 & -1.50 & 0.61 & 0.015 & -1.61 & 0.64 & 0.01 \\
\hline Birthday Quarter 4 & -0.28 & 0.72 & 0.694 & -0.71 & 0.74 & 0.34 \\
\hline \multicolumn{7}{|l|}{ Premier League } \\
\hline Bundesliga & -7.24 & 0.82 & $<0.001$ & -6.83 & 0.86 & $<0.001$ \\
\hline LaLiga & -4.64 & 0.93 & $<0.001$ & -4.63 & 0.92 & $<0.001$ \\
\hline Ligue 1 & -8.66 & 0.80 & $<0.001$ & -8.81 & 0.82 & $<0.001$ \\
\hline Serie A & -6.76 & 0.79 & $<0.001$ & -6.51 & 0.79 & $<0.001$ \\
\hline \multicolumn{7}{|l|}{ Goalkeeper } \\
\hline Defender & 1.85 & 0.62 & 0.003 & 2.54 & 0.69 & $<0.001$ \\
\hline Attacking Midfielder & 7.03 & 1.06 & $<0.001$ & 9.06 & 1.10 & $<0.001$ \\
\hline Midfielder & 3.82 & 0.73 & $<0.001$ & 4.98 & 0.78 & $<0.001$ \\
\hline Forward & 5.38 & 0.91 & $<0.001$ & 7.64 & 0.98 & $<0.001$ \\
\hline Age & -0.18 & 0.05 & 0.001 & 0.33 & 0.06 & $<0.001$ \\
\hline Constant & 29.01 & 2.12 & $<0.001$ & 18.05 & 2.20 & $<0.001$ \\
\hline $\mathrm{R}^{2}$ & \multicolumn{3}{|c|}{0.33} & \multicolumn{3}{|c|}{0.36} \\
\hline $\mathrm{F}$ & \multicolumn{3}{|c|}{$34.39(p<0.001)$} & \multicolumn{3}{|c|}{$42.98(p<0.001)$} \\
\hline
\end{tabular}

\section{Discussion}

This study highlights the team variables and position of players that most influence the market value of professional footballers in Europe. In this regard, existing literature has provided the most important key performance indicators when determining the market value of footballers [29].

Firstly, clubs that play in the UEFA Champions League (ranked in the top positions of their leagues) have significantly higher average salaries than the clubs that compete in the UEFA Europa League competition or do not compete in any international competition (bottom clubs). Kesenne [30] argued that there is a tendency toward higher salaries when teams dispute European competitions, since they rely on longer and more economically attractive contracts to retain the best players and guarantee the competitiveness of the club. In addition, these teams usually have international players. This provides support for a shop window effect [31], as it has previously been shown that the clubs with the most international players (which is common among top and UEFA Champions League teams) receive higher salaries $[14,15,32]$. In addition, it has been demonstrated that top teams contain players from countries in the top positions of the FIFA ranking, while bottom teams include players from the lowest positions [33]. Although this study concludes that the position of a club in the FIFA ranking does not have a direct relationship with the price of a player, the descent of a club by 1 FIFA position reduces the value of a player by 0.08 million. 
The differences observed between the Premier League and the remaining leagues is explained by the distribution of television rights. In the 2015/2016 season, the Premier League enjoyed a total income of $€ 2130$ million for television rights, compared to $€ 971$ million for LaLiga, $€ 924$ million for Serie A, $€ 708$ million for Bundesliga, and $€ 508$ million for Ligue 1. In the current season, the Premier League ( $€ 2754$ million; $+29.30 \%$ ) has increased this difference with respect to all other leagues (LaLiga ( $€ 1247$ million; $+28.42 \%$ ); Serie A (€924 million; $+0 \%$ ); Ligue 1 ( $€ 578$ mill, 13.78\%)), with the exception of the Bundesliga ( $€ 1002$ million; $+41.52 \%$ ). This is the main cause in the imbalance found in the value of the teams in the different leagues, both current and maximum [25].

When analysing only the teams classified in the UEFA Champions League, different conclusions are reached. While the Premier League has a greater average value of its players, the differences between the Premier League and LaLiga disappear when only the value of players of the teams classified in the UEFA Champions League is taken into account. These findings can be largely explained by the entry into force of collective bargaining for television rights. In this case, LaLiga was the last competition among those analysed in this study that incorporated a centralised management of retransmission revenues [25]. Previously, LaLiga teams had negotiated their television rights on an individual basis, causing great financial inequality and the total financial dominance of Real Madrid and Barcelona, leading to over-performance in the UEFA Champions League.

Serrano and colleagues [34] showed that the economic value of the team is the most determining factor in the demand for professional football. Therefore, it is highly probable that the differences found among leagues will lead to a greater interest in the Premier League in their domestic competition, while LaLiga will have a great weight at the level of European competitions. However, the stability that the Premier League has achieved as the competition with the highest value of its players in general terms could lead it to overtake LaLiga in the UEFA Champions League, as well.

A factor that could bias this research is how other different factors could affect the perceived market value. Kiefer [35] analyzed the impact of different independent variables in media coverage, the interest of sports journalism, social media followers, and perceived market value of players (via Transfermarkt) during UEFA Euro 2012. Among these variables, we can find performance and playing variables as goals, assist minutes of playing, yellow cards, committed and suffered fouls; on the other hand, there are other factors such as age, the internationality of players, minutes of playing, transfer of players last summer and internet users and penetration (based on the internet activity of the country every player comes from). The researcher found that the factors age, round achieved, goals, previous transfer, and minutes of playing had a significant effect on perceived market value. Despite the fact that our research has been carried out using the data of one season, not a tournament, these variables have to be included in future studies.

Whatever the case, the economic value of players and teams has proven to be a determining factor for the attractiveness of professional football [36,37], as well as for sports performance [38]. While the internal financial balance of European leagues has increased [39], the competitive balance has diminished [38], and the differences in mean value among leagues have increased. Recent studies suggested that competitive balance has been adversely affected by the new regulations, such us financial fair play, especially in LaLiga, Premier League, and Bundesliga [39]. Therefore, international football entities such as UEFA must take into account the financial balance between competitions, and they must do so not only at the domestic level, as the attractiveness and balance of European competitions may be directly affected.

This study has shown how the real economic value of leagues, as well as other variables such as playing position, could directly affect the perceived market value of players. Also, players that do not play a European competition usually have a lower perceived market value, even if their performance is good overall. Thus, a stronger economic balance of European leagues will lead to a higher sustainability of domestic leagues, building a stronger competitive balance and helping smaller teams to obtain greater income. If these policies do not change in the medium-long term, the most powerful leagues and clubs will continue to own the best perceived economic values. 
Author Contributions: Conceptualization, J.L.F., P.B., A.F.-L., and J.S.-S.; methodology J.G.-U.; formal analysis, J.G.-U. and L.E.d.l.R.; resources, J.L.F. and J.S.-S.; data curation, J.L.F. and L.E.d.1.R.; writing-original draft preparation, J.L.F., P.B., and A.F.-L.; writing-review and editing, A.F.L. All authors have read and agreed to the published version of the manuscript.

Funding: J.G.-U. acknowledges the “Fondo Europeo de Desarrollo Regional, Programa Operativo de la Región de Castilla-La Mancha" (2018/11744) for funding the development of his research.

Conflicts of Interest: The authors declare no conflict of interest.

\section{References}

1. Deprez, D.N.; Fransen, J.; Lenoir, M.; Philippaerts, R.M.; Vaeyens, R. A retrospective study on anthropometrical, physical fitness, and motor coordination characteristics that influence dropout, contract status, and first-team playing time in high-level soccer players aged eight to eighteen years. J. Strength Cond. Res. 2015, 29, 1692-1704. [CrossRef] [PubMed]

2. Lovell, R.; Towlson, C.; Parkin, G.; Portas, M.; Vaeyens, R.; Cobley, S. Soccer player characteristics in English lower-league development programmes: The relationships between relative age, maturation, anthropometry and physical fitness. PLoS ONE 2015, 10, e0137238. [CrossRef] [PubMed]

3. Williams, A.M.; Reilly, T. Talent identification and development in soccer. J. Sports Sci. 2000, 18, 657-667. [CrossRef] [PubMed]

4. Boone, J.; Vaeyens, R.; Steyaert, A.; Vanden Bossche, L.; Bourgois, J. Physical fitness of elite Belgian soccer players by player position. J. Strength Cond. Res. 2012, 26, 2051-2057. [CrossRef]

5. di Salvo, V.; Baron, R.; Tschan, H.; Calderon Montero, F.J.; Bachl, N.; Pigozzi, F. Performance characteristics according to playing position in elite soccer. Int. J. Sports Med. 2006, 28, 222-227. [CrossRef]

6. Dobson, S.; Gerrard, B. The determination of player transfer fees in English professional soccer. J. Sport Manag. 1999, 13, 259-279. [CrossRef]

7. Deutscher, C.; Büschemann, A. Does consistency pay off financially? Evidence from the Bundesliga. J. Sports Econ. 2016, 17, 27-43. [CrossRef]

8. Garcia del Barrio, P.; Pujol, F. Pay and Performance in the Spanish Soccer League: Who Gets the Expected Monopsony Rents? University of Navarra: Pamplona, Spain, 2004.

9. Bryson, A.; Frick, B.; Simmons, R. The returns to scarce talent: Footedness and player remuneration in European soccer. J. Sports Econ. 2013, 14, 606-628. [CrossRef]

10. Bachan, R.; Reilly, B.; Witt, R. Team performance and race: Evidence from the English and French national soccer teams. Appl. Econ. 2014, 46, 1535-1546. [CrossRef]

11. Hoffmann, R.; Chew, L.G.; Ramasamy, B. The socio-economic determinants of international soccer performance. J. Appl. Econ. 2002, 5, 253-272. [CrossRef]

12. Pedace, R. Earnings, performance, and nationality discrimination in a highly competitive Labor market as an analysis of the English professional soccer league. J. Sport Econ. 2008, 9, 115-140. [CrossRef]

13. Schokkaert, J. Football clubs' recruitment strategies and international player migration: Evidence from Senegal and South Africa. Soccer Soc. 2016, 17, 120-139. [CrossRef]

14. Lehmann, E.; Schulze, G. What does it take to be a star?-The role of performance and the media for German soccer players. Appl. Econ. Q. 2008, 54, 59-70. [CrossRef]

15. Lucifora, C.; Simmons, R. Superstar effects in sport: Evidence from Italian soccer. J. Sports Econ. 2003, 4, 35-55. [CrossRef]

16. Herm, S.; Callsen-Bracker, H.M.; Kreis, H. When the crowd evaluates soccer players' market values: Accuracy and evaluation attributes of an online community. Sport Manag. Rev. 2014, 17, 484-492. [CrossRef]

17. Müller, O.; Simons, A.; Weinmann, M. Beyond crowd judgments: Data-driven estimation of market value in association football. Eur. J. Oper. Res. 2017, 263, 611-624.

18. Prpić, J.; Shukla, P.P.; Kietzmann, J.H.; McCarthy, I.P. How to work a crowd: Developing crowd capital through crowdsourcing. Bus. Horiz. 2015, 58, 77-85. [CrossRef]

19. Peeters, T. Testing the Wisdom of Crowds in the field: Transfermarkt valuations and international soccer results. Int. J. Forecast. 2018, 34, 17-29. [CrossRef]

20. Torgler, B.; Schmidt, S.L. What shapes player performance in soccer? Empirical findings from a panel analysis. Appl. Econ. 2007, 39, 2355-2369. [CrossRef] 
21. Richau, L.; Follert, F.; Emrich, M.F. Performance indicators in football: The importance of actual performance for the market value of football players. Sciamus Sport und Management Jahrestagung des Arbeitskreises Sportökonomie 2019, 23, 41-67.

22. Frenger, M.; Follert, F.; Richau, L.; Emrich, E. Follow me ... on the relationship between social media activities and market values in the German Bundesliga. Work. Pap. Eur. Inst. Socioecon. 2019, 32, 4-12.

23. Lorenz, J.; Rauhut, H.; Schweitzer, F.; Helbing, D. How social influence can undermine the wisdom of crowd effect. Proc. Natl. Acad. Sci. USA 2011, 108, 9020-9025. [CrossRef] [PubMed]

24. Prockl, F.; Frick, B. Information Precision in Online Communities: Player Valuations on www.Transfermarkt. De. Int. J. Sport Financ. 2018, 13, 319-335.

25. Carreras, M.; Garcia, J. TV Rights, Financial Inequality, and Competitive Balance in European Football: Evidence from the English Premier League and the Spanish LaLiga. Int. J. Sport Financ. 2018, 13, 201-224.

26. Doyle, J.R.; Bottomley, P.A. Relative age effect in elite soccer: More early-born players, but no better valued, and no paragon clubs or countries. PLoS ONE 2018, 13, e0192209. [CrossRef]

27. Pérez-González, B.; Fernández-Luna, A.; Vega, P.; Burillo, P. The relative age effect: Does it also affect perceived market value? The case of the Spanish LFP (Professional Football League). J. Phys. Educ. Sport 2018, 18, 1408-1411.

28. Cohen, J. A power primer. Psychol. Bull. 1992, 112, 155-159. [CrossRef]

29. Wicker, P.; Prinz, J.; Weimar, D.; Deutcher, C.; Upmann, T. No pain, no gain? Effort and productivity in professional soccer. Int. J. Sport Financ. 2013, 8, 124-139.

30. Kesenne, S. Revenue sharing and absolute league quality; talent investment and talent allocation. Scott. J. Political Econ. 2015, 62, 51-58. [CrossRef]

31. Simmons, R.; Deutscher, C. The economics of the World Cup. In The Oxford Handbook of Sports Economics; Kahane, L., Shmanske, S., Eds.; Oxford University Press: Oxford, UK, 2012.

32. Franck, E.; Nüesch, S. Mechanism of superstar formation in German soccer: Empirical evidence. Eur. Sport Manag. Q. 2018, 8, 145-164. [CrossRef]

33. Majewski, S. Identification of factors determining market value of the most valuable football players. J. Manag. Bus. Adm. 2016, 24, 91-104. [CrossRef]

34. Serrano, R.; García-Bernal, J.; Fernández-Olmos, M.; Espitia-Escuer, M.A. Expected quality in European football attendance: Market value and uncertainty reconsidered. Appl. Econ. Lett. 2015, 22, 1051-1054. [CrossRef]

35. Kiefer, S. The impact of the Euro 2012 on popularity and market value of football players. Int. J. Sport Financ. 2014, 9, 95-110.

36. Gerhards, J.; Mutz, M. Who wins the championship? Market value and team composition as predictors of success in the top European football leagues. Eur. Soc. 2017, 19, 223-242. [CrossRef]

37. Deutscher, C.; Ötting, M.; Schneemann, S.; Scholten, H. The Demand for English Premier League Soccer Betting. J. Sports Econ. 2019, 20, 556-579. [CrossRef]

38. Pawlowski, T.; Breuer, C.; Hovemann, A. Top clubs' performance and the competitive situation in European domestic football competitions. J. Sports Econ. 2010, 11, 186-202. [CrossRef]

39. Plumley, D.; Ramchandani, G.M.; Wilson, R. The unintended consequence of Financial Fair Play: An examination of competitive balance across five European football leagues. Sport Bus. Manag. 2019, 9, 118-133. [CrossRef]

(C) 2020 by the authors. Licensee MDPI, Basel, Switzerland. This article is an open access article distributed under the terms and conditions of the Creative Commons Attribution (CC BY) license (http://creativecommons.org/licenses/by/4.0/). 